\title{
Factors associated with disordered gambling in Finland
}

\author{
Sari Castrén ${ }^{1,2^{*}}$, Syaron Basnet ${ }^{1,4}$, Anne H Salonen ${ }^{1}$, Maiju Pankakoski ${ }^{1}$, Jenni-Emilia Ronkainen ${ }^{1}$, Hannu Alho ${ }^{1,3}$ \\ and Tuuli Lahti ${ }^{1,4}$
}

\begin{abstract}
Background: The purpose of this study was to compare the socio-demographic characteristics of non-problem gamblers, problem gamblers and pathological gamblers, to investigate the association between gambling related factors and perceived health and well-being among the three subgroups of gamblers, and to analyse simultaneously socio-demographic characteristics, gambling related factors and perceived health and well-being and the severity of disordered gambling (problem gamblers and pathological gamblers).
\end{abstract}

Methods: The data were collected through a nationwide telephone survey in 2011. Participants were selected through a random population sample of 15-74-year-old Finns. From that sample, persons with any past-year gambling involvement $(\mathrm{N}=3451)$ were selected for a subsample for the descriptive and inferential analysis in the present paper. Gambling was assessed using the South Oaks Gambling Screen. Statistical significance was determined by chi-squared tests. The odds ratio and effect size were computed by using multivariate-adjusted multinomial logistic regression analysis.

Results: The most significant socio-demographic characteristics (male gender, young age, education $\leq 12$ years), gambling related factors (slot machine gambling, internet gambling) and perceived health and well-being (feeling lonely, smoking daily, risky alcohol consumption, mental health problems) explained 22.9 per cent of the variation in the severity of disordered gambling.

Conclusion: Male gender and loneliness were found to be associated with problem gambling in particular, along with smoking and risky alcohol consumption. Mental health problems and risky alcohol consumption were associated with pathological gambling. These identified associations between disordered gambling, mental health problems and risky alcohol consumption should be taken into consideration when implementing screenings of disordered gambling.

Keywords: Disordered gambling, Pathological gambling, Population survey, Problem gambling, Public health, South Oaks Gambling Screen

\section{Introduction}

Throughout the history people have been gambling. However, with the recent expansion of opportunities to gamble, gambling has become more problematic [1]. Today gamblers have the possibility to gamble more often and more frequently than ever before. Thus

\footnotetext{
* Correspondence: sari.castren@thl.fi

${ }^{1}$ National Institute for Health and Welfare, Department of Mental Health and Substance Abuse Services, P.O. Box 30 Helsinki, FO 00271 Finland ${ }^{2}$ Institute of Behavioural Sciences, University of Helsinki, Faculty of Behavioural Sciences, Helsinki, Finland

Full list of author information is available at the end of the article
}

disordered gambling (DG) has become a serious public health concern worldwide. Most individuals gamble without any negative consequences due to gambling, but often excessive gambling leads to several adverse consequences to the gamblers, their significant others and to their communities [2]. The social and economic costs of DG are multitudinous. For example, the annual social cost of DG in the US is estimated to be 5 billion dollars [3,4].

The most severe pattern of DG is pathological gambling (PG) which is categorized by the Diagnostic and Statistical Manual of Mental Disorders (DSM-IV) as a

\section{() Biomed Central}


disorder of impulse control [5]. PG meets at least five of the ten criteria listed in DSM-IV. In addition to PG, DSM-IV can also be used to identify a milder form of disordered gambling, problem gambling. Problem gambling meets 3-4 of the ten criteria listed in DSM-IV. Epidemiological studies estimate that the prevalence of PG is between $1.1 \%$ and $5.3 \%$ among the adult population [6-9]. Recent analysis by Williams and colleagues [10] stated that the standardized past-year prevalence of PG varied from $0.5 \%$ to $7.6 \%$ internationally. Currently in Finland the past-year prevalence of PG is estimated to be $1 \%$, and problem gambling $1.7 \%$ [11].

DG and its consequences are often hidden, complex, multifaceted and multidimensional phenomena [12]. The individuals with particular socio-demographic characteristics seem to be at risk for the development of DG. For example male gender, young age, low socioeconomic status, low educational level, divorced or single marital status, and in some studies, a minority status [3,13-16] have been linked to an increased risk for DG. Psychiatric comorbid illnesses have also been recognized to be common amongst persons suffering from DG [17-19]. For example, severe depression, mood disorders, the use of nicotine and alcohol use disorder have been associated with DG [20]. Along with specific sociodemographic characteristics and psychiatric comorbid illnesses, availability of gambling venues is also associated with the prevalence of gambling [15,21,22]. These associations have been studied broadly worldwide. However, amount of studies from Finland are so far rather limited [11]. Therefore, more information is needed in order to develop and establish effective methods for prevention and treatment of DG in a Finnish culturalcontext. Our research establishes new information as only few studies have earlier examined simultaneously socio-demographic characteristics, gambling related factors, as well as perceived health and well-being [9].

Given the rapid growth and the increasing availability of gambling in varying frequencies and forms at the present, gambling has become more accessible worldwide $[8,23,24]$, both internationally and in Finland. In Finland especially with a large amount of slot machines available as well as with a growing availability of unregulated internet sites worldwide. As excessive gambling has the potential to become disordered, it is important to understand which groups have elevated risk to develop DG. Therefore, in this study we first compare the socio-demographic characteristics (gender, age, education, marital status) of non-problem gamblers, problem gamblers and PG's. Second, we investigate the association between gambling related factors (onset age, problem gambler close by, gambling frequency, money gambled and type of gambling) among the subgroups of gamblers. Third, we investigate the association between perceived health and well-being (loneliness, smoking, alcohol consumption, mental health and general health) among the subgroups of gamblers. Fourth, we analyse simultaneously socio-demographic characteristics, gambling related factors and perceived health and well-being and the severity of DG. These analyses are necessary for to find out the possible vulnerability factors related to DG and to develop early screenings of DG.

\section{Methods}

This study is based on a cross-sectional nationwide telephone survey entitled the Finnish Gambling 2011 [11]. The data were collected between 3rd October 2011 and 14th January 2012. Participants were selected from the Finnish Population Register by using a random sample of 15-74-year-old Finns. The sample size was 16,000, of whom 11,129 had a registered telephone number. Before the telephone interview, the participants received an introductory letter describing the purpose of the study. The participants, whose phone number was not in the Finnish Population Register, were sent a letter requesting their willingness to participate in the survey. Eventually a total of 4,484 participants completed the study. From that sample, participants with any past-year gambling involvement $(\mathrm{N}=3,451)$ were drawn for this study. The sampling weights based on age, gender and residency of the Finnish population [11] were applied to all descriptive and inferential analysis. The ethics committee of the National Institute for Health and Welfare approved the research protocol.

\section{Measurements}

\section{Gambling behaviour}

Gambling behaviour was measured by using a 12-month time frame with the South Oaks Gambling Screen (SOGS) originally developed by Lesieur and Blume [24], with a total score of 20. SOGS is scored as: $0-2=$ non-problem gamblers, 3-4 = problem gamblers, $\geq 5$ = probable pathological gamblers. The Cronbach alpha for the SOGS was 0.913.

\section{Socio-demographic characteristics}

Socio-demographic characteristics analysed in this study included gender, age, education and marital status (Table 1).

\section{Gambling related factors}

Gambling related factors were onset age, problem gambler (significant other) gambling frequency, gambling expenditure and the types of games gambled (Table 2). The following questions were used with each factor: a) onset age, with the question of, 'When did you start gambling?' as a continuous factor; b) gambling of significant others (father, mother, sister or brother, grandparent, spouse, child, close friend) with the question of 'Do any of the following people have or have had problems 
Table 1 Association between socio-demographic characteristics among the subgroups of gamblers

\begin{tabular}{|c|c|c|c|c|c|}
\hline & $\begin{array}{l}\text { All gamblers } \\
\qquad \mathrm{N}=3451\end{array}$ & $\begin{array}{r}\text { Non-problem gamblers } \\
\qquad n=3345\end{array}$ & $\begin{array}{r}\text { Problem gamblers } \\
n=67\end{array}$ & $\begin{array}{r}\text { Pathological gamblers } \\
n=39\end{array}$ & $\mathrm{X}^{2}$ test \\
\hline Characteristics & $\%$ & $\%$ & $\%$ & $\%$ & \\
\hline \multicolumn{6}{|l|}{ Gender } \\
\hline Male & 53.2 & 52.2 & 85.7 & 70.0 & $\begin{array}{c}X^{2}=35.374, d f=2 \\
p \leq 0.001\end{array}$ \\
\hline Female & 46.8 & 47.8 & 14.3 & 30.0 & \\
\hline \multicolumn{6}{|l|}{ Age, in years } \\
\hline $15-24$ & 14.2 & 13.9 & 21.7 & 25.6 & \\
\hline $25-34$ & 18.2 & 17.9 & 23.2 & 28.2 & $\begin{array}{c}X^{2}=15.061, d f=6 \\
p=0.019\end{array}$ \\
\hline $35-49$ & 26.9 & 27.0 & 26.1 & 15.4 & \\
\hline$\geq 50$ & 40.7 & 41.1 & 29.0 & 30.8 & \\
\hline \multicolumn{6}{|l|}{ Education } \\
\hline$\leq 12$ years education & 40.0 & 39.5 & 57.1 & 47.5 & $\begin{array}{c}X^{2}=9.792, d f=2 \\
p=0.007\end{array}$ \\
\hline$>12$ years education & 60.0 & 60.5 & 42.9 & 52.5 & \\
\hline \multicolumn{6}{|l|}{ Marital status } \\
\hline Married/registered relationship & 48.1 & 48.9 & 27.9 & 25.0 & $\begin{array}{c}X^{2}=31.040, d f=6 \\
p \leq 0.001\end{array}$ \\
\hline Cohabiting & 17.9 & 18.0 & 11.8 & 25.0 & \\
\hline Separated/divorced/widowed & 10.2 & 10.0 & 16.2 & 15.0 & \\
\hline Single & 23.7 & 23.1 & 44.1 & 35.0 & \\
\hline
\end{tabular}

Significance $(p)$ is determined by chi-squared $\left(X^{2}\right)$ test; The data were weighted based on gender, age and residency.

with gambling?' with answering options (yes, no, do not know). This was a categorical factor, that was recorded into a dichotomous factor; c) gambling frequency, which was recoded into two categories (once a week or more/ rarely than weekly); d) gambling expenditure, with the question of 'How much money did you spend into gambling during the past week?'. This was a continuous factor, that was recoded into three categories (do not know, $0-5 €, 5 €$ or more); e) type of gambling with five options: lotto, scratch cards, slot machines, casino gambling or gambling in the internet during the past 12 months, as a categorical factor.

\section{Perceived health and well-being}

Factors related to health and well-being included gamblers' perceptions of loneliness, daily smoking, risky alcohol consumption, mental health and general health (Table 3). Loneliness was measured by using a question 'Do you feel lonely?' with five options, which were recoded into two categories (all the time/often and sometimes/rarely/never). Frequency of smoking was evaluated by using a question 'Have you smoked during the past 12 months?' with a 3-point Likert scale (daily, randomly, not at all). Random smokers and non-smokers were grouped into the same group for the analysis. Consumption of alcohol was measured by using the modified version of the Alcohol Use Disorders Identification Test, AUDIT-C [25]. AUDIT-C is a 3-item screen, which is used to identify those persons who are hazardous drinkers or have active alcohol use disorders (including alcohol abuse or dependence). The AUDIT-C is a 5-point Likert scale with scoring: $\mathrm{a}=0$ point, $\mathrm{b}=1$ point, $\mathrm{c}=2$ points, $\mathrm{d}=3$ points and $\mathrm{e}=4$ points. In this study, the total scores of AUDIT-C were counted by summing up the points for each item, and cut-off points recommended by Seppä [26] were used to define risky drinking among males (score $\geq 6$ ) and females (score $\geq 5$ ). The Cronbach alpha for the AUDIT-C was 0.611 .

The mental health of the participants was assessed by using the Mental Health Inventory (MHI-5) [27] comprising the following five items: nervousness, blues, jollity, calmness and happiness. MHI- 5 was measured by using a 6-point Likert scale scoring: $1=$ all of the time, $2=$ most of the time, $3=$ a good bit of the time, $4=$ some of the time, $5=$ a little of the time, $6=$ none of the time. The total scores of MHI- 5 factors were calculated by summing up the score of each item and the sums (range 4-30) were scaled into 1-100. Cut-off score of 52 or less was used: lower scores indicate clinically significant mental health problems [28]. The Cronbach alpha for the MHI-5 was 0.768 . General health was inquired by 
Table 2 Association between gambling related factors and subgroups of gamblers

\begin{tabular}{|c|c|c|c|c|c|}
\hline & All gamblers & Non-problem gamblers & Problem gamblers & Pathological gamblers & $\mathrm{X}^{2}$ test \\
\hline & $\mathrm{N}=3451$ & $\mathrm{n}=3345$ & $n=67$ & $n=39$ & \\
\hline Gambling related factors & $\%$ & $\%$ & $\%$ & $\%$ & \\
\hline Onset age, years & & & & & $\begin{array}{c}X^{2}=22.174, d f=2 \\
p \leq 0.001\end{array}$ \\
\hline$<18$ & 56.6 & 55.8 & 75.7 & 82.5 & \\
\hline$\geq 18$ & 43.4 & 42.2 & 24.3 & 17.5 & \\
\hline Problem gambler (significant other) & & & & & $\begin{array}{c}X^{2}=33,177, d f=2 \\
p \leq 0.001\end{array}$ \\
\hline Yes, at least one & 19.9 & 19.2 & 37.1 & 47.5 & \\
\hline No, none & 80.1 & 80.8 & 62.9 & 52.5 & \\
\hline \multicolumn{6}{|l|}{ Gambling frequency } \\
\hline Once a week or more & 45.8 & 44.4 & 88.4 & 77.5 & $\begin{array}{c}X^{2}=69.094, d f=2 \\
p \leq 0.001\end{array}$ \\
\hline Rarely than weekly & 54.2 & 55.6 & 11.6 & 22.5 & \\
\hline \multicolumn{6}{|l|}{ Money gambled, past week } \\
\hline Do not know & 19.6 & 19.5 & 21.4 & 25.6 & \\
\hline 0-5 euro & 50.8 & 52.2 & 10.0 & 17.9 & $\begin{array}{c}X^{2}=80.405, d f=4 \\
p \leq 0.001\end{array}$ \\
\hline$>5$ euro & 29.5 & 28.3 & 68.6 & 56.5 & \\
\hline \multicolumn{6}{|l|}{ Played lotto, past 12 months } \\
\hline Yes & 87.5 & 87.6 & 87.1 & 80.0 & $\begin{array}{c}X^{2}=2.112, d f=2 \\
p=0.348\end{array}$ \\
\hline No & 12.4 & 12.4 & 12.9 & 20.0 & \\
\hline \multicolumn{6}{|l|}{ Played scratch cards, past 12 months } \\
\hline Yes & 44.0 & 43.4 & 62.3 & 62.5 & $\begin{array}{c}X^{2}=15.451, d f=2 \\
p \leq 0.001\end{array}$ \\
\hline No & 56.0 & 56.6 & 37.7 & 37.5 & \\
\hline \multicolumn{6}{|l|}{ Played slot machines, past 12 months } \\
\hline Yes & 42.4 & 40.7 & 90.0 & 82.5 & $\begin{array}{c}X^{2}=94.750, d f=2 \\
p \leq 0.001\end{array}$ \\
\hline No & 57.6 & 59.3 & 10.0 & 17.5 & \\
\hline \multicolumn{6}{|l|}{ Played casino, past 12 months } \\
\hline Yes & 2.8 & 2.4 & 7.2 & 30.8 & $\begin{array}{c}X^{2}=117.664, d f=2 \\
p \leq 0.001^{\dagger}\end{array}$ \\
\hline No & 97.2 & 97.6 & 92.8 & 69.2 & \\
\hline \multicolumn{6}{|l|}{ Internet gambling, past 12 months } \\
\hline Yes & 24.5 & 23.6 & 48.6 & 55.0 & $\begin{array}{c}X^{2}=43.377, d f=2 \\
p \leq 0.001\end{array}$ \\
\hline No & 75.5 & 76.4 & 51.4 & 45.0 & \\
\hline
\end{tabular}

Significance $(\mathrm{p})$ is determined by chi-squared $\left(\mathrm{X}^{2}\right)$ test; ${ }^{\dagger} 33.3 \%$ cells have expected count less than 5 ; the data were weighted based on gender, age and residency.

using a question 'How is your general health at present?', with five options recoded into three categories (bad/ somewhat bad, average and good/somewhat good).

\section{Statistical analysis}

The analyses were carried out in two steps. First, chisquare test was used to compare the statistical significance (p) of the associations of the categorical factors and the three subgroups of gamblers (Tables 1, 2 and 3). The factors for these bivariate analyses were chosen as based on strong evidence gained from the previous studies. All categorical factors are presented using frequencies and percentages.

Then factors associated with the severity of DG were explored using a multivariate-adjusted multinomial logistic regression analysis (multinomial regression analysis). 
Table 3 Association between perceived health and well-being and subgroups of gamblers

\begin{tabular}{|c|c|c|c|c|c|}
\hline & All gamblers & Non-problem gamblers & Problem gamblers & Pathological gamblers & $\mathrm{X}^{2}$ test \\
\hline & $\mathrm{N}=3451$ & $n=3345$ & $\mathrm{n}=67$ & $\mathrm{n}=39$ & \\
\hline Perceived health/well-being & $\%$ & $\%$ & $\%$ & $\%$ & \\
\hline Feeling lonely & & & & & $\begin{array}{c}X^{2}=27.509, d f=2 \\
p \leq 0.001\end{array}$ \\
\hline All the time/often & 17.3 & 16.7 & 38.6 & 30.0 & \\
\hline Never/very rarely/sometimes & 82.7 & 83.3 & 61.4 & 70.0 & \\
\hline Smoking & & & & & $\begin{array}{c}x^{2}=57.468, d f=2 \\
p \leq 0.001\end{array}$ \\
\hline Daily smoking & 19.9 & 18.8 & 48.6 & 47.5 & \\
\hline Not at all/occasionally & 80.1 & 81.2 & 51.4 & 52.5 & \\
\hline \multicolumn{6}{|l|}{ Alcohol risk consumer, AUDIT-C } \\
\hline At risk & 28.3 & 26.9 & 68.8 & 71.4 & $\begin{array}{c}X^{2}=86.394, d f=2 \\
p \leq 0.001\end{array}$ \\
\hline Not at risk & 71.7 & 73.1 & 31.2 & 28.6 & \\
\hline \multicolumn{6}{|l|}{ Mental health, MHI-5 } \\
\hline Clinically significant problem & 3.3 & 3.0 & 8.6 & 17.9 & $\begin{array}{c}X^{2}=33.024, d f=2 \\
p \leq 0.001\end{array}$ \\
\hline No problem & 96.7 & 97.0 & 91.4 & 82.1 & \\
\hline \multicolumn{6}{|l|}{ General health } \\
\hline Bad/somewhat bad & 2.8 & 2.7 & 4.3 & 7.7 & $\begin{array}{c}X^{2}=17.159, d f=4 \\
p=0.005^{\dagger}\end{array}$ \\
\hline Average & 13.0 & 12.8 & 27.1 & 10.3 & \\
\hline Good/somewhat good & 84.2 & 84.5 & 68.6 & 82.0 & \\
\hline
\end{tabular}

AUDIT-C, the Alcohol Use Disorders Identification Test, score for risk consumption $\geq 5$ among women and $\geq 6$ among men; $M H I-5$, the Mental Health Inventory, scale $1-100$, clinically significant problem $\leq 52$. Significance $(p)$ is determined by chi-squared $\left(X^{2}\right)$ test; the data were weighted based on gender, age and residency; ${ }^{\dagger} 22,2 \%$ cells have expected count less than 5 .

In this analysis, problem gamblers and PG's were compared with non-problem gamblers. Selected factors consisted of socio-demographic characteristics, gambling related factors and perceived health and well-being and they were included in the final model simultaneously (Table 4).

Socio-demographic characteristics (gender, age and education) used in the model carry strong theoretical evidence from past studies. To precisely optimise the model, two game types, which represent the most widespread accessibility and addictive potential, slot machine and internet gambling, were included into the model as gambling related factors. Finally, loneliness, daily smoking, risky alcohol consumption and overall mental health (MHI-5) represented significant factors related to perceived health and well-being.

The best fitting model was chosen by exploring different combinations of factors and comparing different models using the coefficient of determination ( $\mathrm{R}$ squared). Results of the multinomial regression model are presented as odd ratios (OR) and their corresponding 95\% confidence intervals (CI). Goodness of fit was assessed using the Nagelkerke's $R^{2}$.

\section{Results}

Bivariate analysis: associations between socio-demographic characteristics and the subgroups of gamblers

The socio-demographic characteristics of the different subgroups of gamblers are summarized in Table 1 . There were 3,451 participants (53.2\% males and 46.8\% females) with the mean age of 44.27 years $(S D=15.97)$. Overall, there were a greater proportion of males than females in all of the subgroups of gamblers. Compared with non-problem gamblers $(52.2 \%)$ the percentage of males was greater amongst problem gamblers $(85.7 \%)$ and PG's $(70.0 \%),\left(\chi^{2}=35.374, d f=2, \mathrm{p}<0.001\right)$. According to our results, PG's were younger compared to the other subgroups of gamblers $\left(\mathrm{x}^{2}=15.061, d f=2\right.$, $\mathrm{p}<0.019)$. There were statistically significantly more gamblers with twelve or less years of education in the problem gambling group (57.1\%) compared to nonproblem gamblers $(39.5 \%)$ and to PG's $(47.5 \%),\left(x^{2}=\right.$ 9.792, $d f=2, \mathrm{p}<0.007)$. Most of the non-problem gamblers $(66.9 \%)$ were married or lived in a registered relationship or were cohabiting, while the corresponding figures for problem gamblers were $39.7 \%$ and for PG's $50.0 \%$. 
Table 4 Simultaneously analysed factors: socio-demographic characteristics, gambling related factors and perceived health and well-being and the severity of disordered gambling (Problem and Pathological gambling)

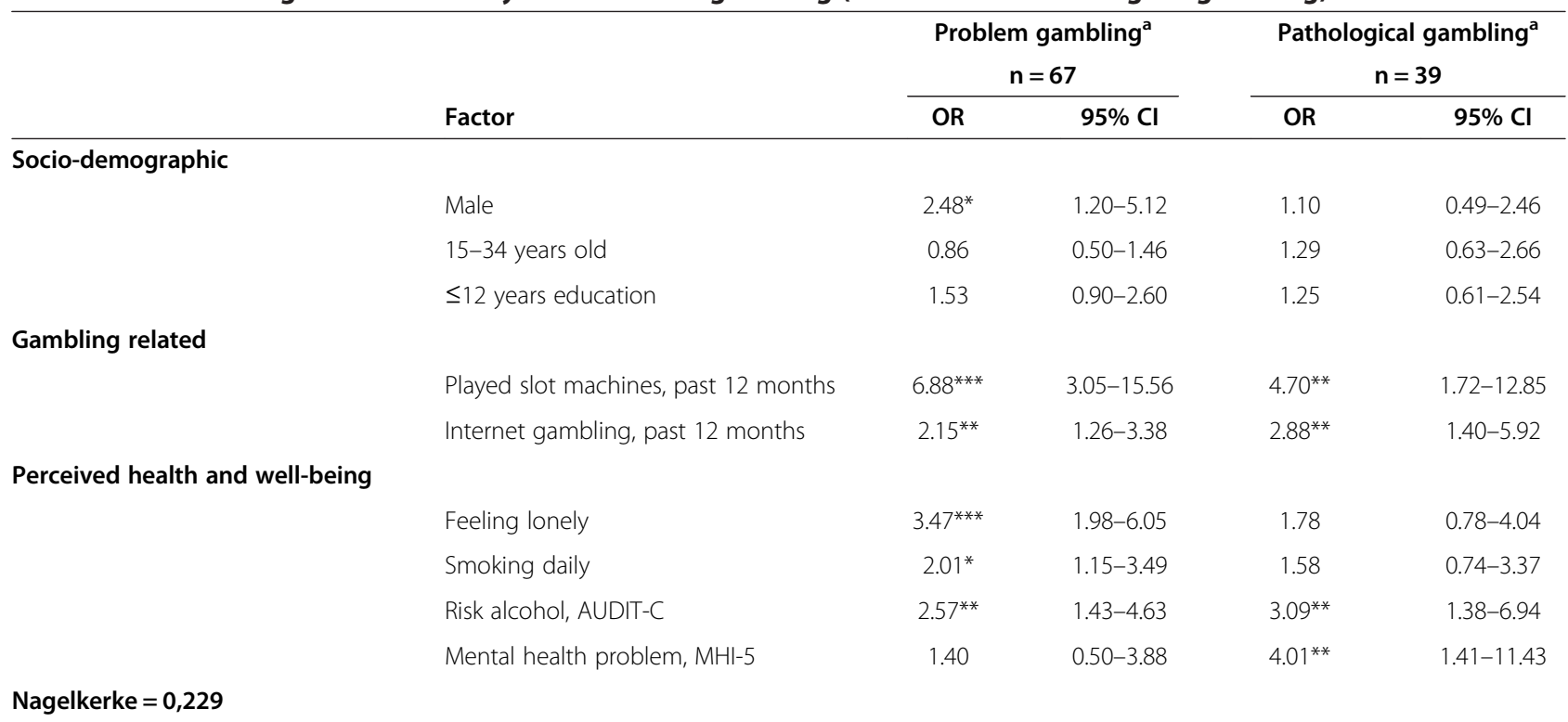

${ }^{a}$ Reference group: Non-problem gamblers $(\mathrm{n}=3345)$; The data $(\mathrm{N}=3451)$ were weighted based on gender, age and residency; Multivariate-adjusted multinomial logistic regression analysis; ${ }^{*}<0.05,{ }^{* *}<0.01,{ }^{* * *}<0.001 ;$ AUDIT-C, the Alcohol Use Disorders Identification Test, score for risk consumption $\geq 5$ among women and $\geq 6$ among men; MHI-5, the Mental Health Inventory, scaled into $1-100$, clinically significant problem $\leq 52$.

Bivariate analysis: associations between gambling related factors and the subgroups of gamblers

Association between gambling related factors and the subgroups of gamblers are presented in Table 2. Onset age of gambling, namely below 18 years, was lower among problem and PG's than among non-problem gamblers $\left(\mathrm{x}^{2}=22.174, d f=2, \mathrm{p}<0.001\right)$. Problem gamblers and PG's had or have had a problem gambler (significant other) more often than the non-problem gamblers $\left(x^{2}=33.177\right.$, $d f=2, \mathrm{p}<0.001)$. Problem gamblers $(88.4 \%)$ gambled more frequently (once a week or more) as compared to PG's (77.5\%) or non-problem gamblers (44.4\%).

Problem gamblers spent more money on gambling than the other subgroups of gamblers (more than $5 €$ per week). However, the percentage of gamblers who did not know the amount they had spent on gambling was the greatest among PG's ( $\left.\chi^{2}=80.405, d f=2, \mathrm{p}<0.001\right)$.

Lotto was the most often gambled game among all subgroups of gamblers. Non-problem gamblers gambled lotto $(87.6 \%)$ slightly more often than problem gamblers (87.1\%) or PG's (80.0\%), ( $\chi 2=2.112, d f=2, \mathrm{p}<0.348)$. Scratch cards were gambled more frequently by problem gamblers (62.3\%) and PG's (62.5\%) as compared to nonproblem gamblers (43.4\%), ( $\left.\chi^{2}=15.45, d f=2, \mathrm{p}<0.001\right)$. Similarly, slot machine gambling was the most prevalent among problem gamblers: $90.0 \%$ of the problem gamblers, $82.5 \%$ of the PG's and $40.7 \%$ of the non-problem gamblers $\left(x^{2}=94.750, d f=2, \mathrm{p}<0.001\right)$ gambled slot machines. Casino gambling was the most prevalent among PG's (30.8\%) as compared with problem gamblers
(7.2\%) or non-problem gamblers $(2.4 \%),\left(x^{2}=117.664\right.$, $d f=2, \mathrm{p}<0.001)$. Internet gambling was also the most prevalent among PG's (55\%) as compared to problem gamblers $(48.6 \%)$ and non-problem gamblers $(23.6 \%)$.

Bivariate analysis: Perceived health and well-being and the subgroups of gamblers

Associations between perceived health and well-being and the subgroups of gamblers are presented in Table 3. Problem gamblers reported feelings of loneliness more often than the other subgroups of gamblers $\left(\chi^{2}=27.509\right.$, $d f=2, \mathrm{p}<0.001)$. Problem gamblers also smoked slightly more on a daily basis than other subgroups of gamblers $\left(\mathrm{x}^{2}=57.468, d f=2, \mathrm{p}<0.001\right)$. According to our results PG's consumed more alcohol in a risky level (71.4\%) than problem gamblers $(68.8 \%)$ and non-problem gamblers (26.9\%), ( $\left.\chi^{2}=86.394, d f=2, \mathrm{p}<0.001\right)$. PG's also experienced clinically significant mental health problems more often than the other subgroups of gamblers $\left(x^{2}=33.024\right.$, $d f=2, \mathrm{p}<0.001)$. However, with general health, there were no significant differences between the studied subgroups of gamblers. All in all, problem gamblers reported loneliness and smoked tobacco more than PG's. PG's, in turn, consumed alcohol at a risky level and had mental health problems more often than problem gamblers.

Multinomial regression analysis: simultaneously analysed factors and the severity of DG

The simultaneously analysed socio-demographic characteristics, gambling related factors and perceived health 
and well-being and the severity of DG was examined by multinomial regression analysis (Table 4). In this analysis, male gender was the only socio-demographic characteristic that was statistically significantly associated with problem gambling (OR 2.48, CI 1.20-5.12). Young age $(15-35)$ and education $\leq 12$ years were not significantly associated with either problem gambling or PG. Game type was significantly associated with DG. Pastyear slot machine gambling was significantly associated with problem gambling (OR 6.88, CI 3.05-15.56) and PG (OR 4.70, CI 1.72-12.85). Likewise was the past-year internet gambling associated with problem gambling (OR 2.15, CI 1.26-3.38) and PG (OR 2.88, CI 1.40-5.92). Associations with perceived health and well-being, were found to be significant with problem gambling as follows: loneliness (OR 3.47, CI 1.98-6.05), daily tobacco smoking (OR 2.01, CI 1.15-3.49) and risky alcohol consumption (OR 2.57, CI 1.43-4.63). Similarly, risky alcohol consumption was associated with PG statistically significantly (OR 3.09, CI 1.38-6.94). In addition, mental health problems were significantly associated with PG (OR 4.01, CI 1.41-11.43).

In the multinomial model, socio-demographic characteristics (male gender, young age, education $\leq 12$ years), gambling related factors (played slot machines, internet gambling) and perceived health and well-being (loneliness, daily tobacco smoking, risky alcohol consumption, mental health problems) explained $22.9 \%$ of the variation in the severity of DG.

\section{Discussion}

\section{Socio-demographic characteristics}

According to our bivariate analysis, socio-demographic characteristics e.g., male gender, low level of education, single marital status and young age were all associated with DG. Similarly, risky alcohol consumption, smoking and loneliness were all associated with problem gambling and more severe mental health problems with PG. These findings are in line with previous research [29-33].

Young males are characteristically more often sensation seekers and thus they have a higher vulnerability to develop addictions [34-36]. Also in the multinomial regression analysis, a strong association between male gender and severity of DG were found. Even though prevalence of DG is greater in males than females, the progression of DG is faster with females [37]. In our study $30 \%$ of the PG's were females. It has been proposed that the main reasons for females to gamble are often boredom, loneliness and isolation. Thus females tend to seek less adventurous gambling types and choose games that maximize their gambling time $[38,39]$ to offer an escape from feeling isolated and lonely.

In the bivariate analysis, there were significantly more young gamblers (ages 15-24 and 25-34) in both DG subgroups. On the contrary, in a multinomial regression analysis, the age was no longer as strongly associated with the severity of DG, nor was this relationship clearly linear. This can be explained by the inclusion of other explanatory factors in the model, such as other sociodemographic characteristics, as well as gambling and health-related variables.

\section{Gambling related factors}

In the bivariate analysis, onset age of gambling was associated with both subgroups of DG, as stated earlier by Volberg et al. [40]. In addition, our results show problem gamblers to gamble more frequently and to spend more money on gambling on a weekly basis than PG's. On the other hand, most of the PG's did not know how much money they had spent on gambling. Not knowing how much one has spent on gambling may reflect the very nature of the gambling pathology: denial of the problem. According to Williams and Volberg [41,42] 'being ahead or in a winning state' may well reflect gamblers biased perception of a winning state. Biased perception means that wins are well remembered and maximized and losses are forgotten or minimized.

PG's gambled more frequently both internet and casino games than problem gamblers. Problem gamblers in turn preferred slot machine gambling more compared to PG's. This difference could be explained perhaps by PG's chasing losses by larger bets as based on 'gamblers fallacy'. In turn, problem gamblers, that do not meet the full criteria of PG, may have temptation to try their 'luck' with slot machines, perhaps due to their easy accessibility. Slot machine gambling has been reported as the most problem causing type of gambling in Finland [43-45]. In Finland, slot machines are openly scattered in shopping centres, small shops, kiosks, restaurants, casino and casual gambling arcades. This is why a concern has emerged especially towards slot machine gambling. Griffiths [46] classified slot machine gambling as having a high addictive potential due to its fast tempo and other properties. Besides the easy access and availability, slot machines are likely to increase involvement in gambling and the development of DG [47-49]. Casino, internet and slot machine gambling are all classified as addictive gambling types [50,51].

Both subgroups of DG gambled lotto rather frequently. In a Finnish context, lotto is the most popular game type in general. The addictiveness of lotto comes from the structural characteristics of the game. Lotto has the potential to be gambled at various intervals be it yearly, weekly or daily. The low cost chance of winning a very large jackpot prize urges gamblers to buy lotto repeatedly. However, the low event frequency of lotto may explain why other types of gambling are more addictive than lotto [52]. 


\section{Perceived health and well-being}

Based on multinomial regression analysis, a new finding was that problem gamblers in particular, reported to be lonelier than non-problem gamblers or PG's. PG's, on the other hand, reported having more mental health problems than problem gamblers and non-problem gamblers. Loneliness, which was associated with problem gambling, can be seen as less severe than overall problems with mental health. Therefore, detecting loneliness among problem gamblers is important and could be used, for example, as a guiding tool/question in the screening of DG. Loneliness, analysed simultaneously with certain socio-demographic characteristics, such as being a young male, may lead to a more severe form of DG or more severe mental health problems if not tackled early enough. Loneliness [39] may be a result or consequence of gambling, given the fact that this is a cross-sectional design. Both loneliness and social isolation is associated with gambling especially among female gamblers [39]. Boredom, which refers to lack of interest in general, is also linked with gambling $[53,54]$.

According to this study DG's were smoking more and consuming alcohol at risk level more often than nonproblem gamblers. This finding is in line with earlier studies: PG is a frequent comorbid diagnosis among substance abusers and vice versa [55]. In addition to substance abuse, also mental health problems such as depression cooccur at high rates amongst DG's [55].

Our multinomial regression analysis shows that there are certain similarities amongst two subgroups of DG's (e.g. type of games gambled and risky alcohol consumption) and therefore, it would be beneficial to use these identified factors in prevention and early detection programs as one additional guideline. DG may get worse over time if not detected early enough. Thus there is an urgent need to better identify and prevent DG before it becomes more difficult to overcome.

DG and its consequences are often hidden, due to feelings of shame and guilt related to excessive gambling and denial of the problem and therefore can be unrecognized for a considerable time. Thus the early identification of DG within the health care system is often difficult. However, by increasing general health practitioners' awareness of the symptoms and most common comorbidities of DG, early detection and better screening of gambling problems can be increased. Based on our multinomial regression analysis, loneliness, smoking and risky alcohol consumption were found to be associated with problem gambling and should be taken into account when screening and treating DG.

\section{Relevance to public health perspective: prevention, protection and detection}

Moreover, our study's multinomial regression analysis found slot machine gambling to be associated with DG. Slot machine gambling is known to be a game of pure chance and therefore by offering accurate knowledge about the features of the games, such as the existence of erroneous beliefs related to gambling or probabilities of winning in different games, the harms caused by gambling can be reduced and treated [56-62]. Also a recent publication from the European Commission (EC) recommended more clear information to be given about gambling products [63]. The same has been stated in the Reno Model [64]. Therefore, all games, betting and lottery tickets should have a product warning providing information about the harmful effects and possible negative consequences of gambling. Moreover, anti-stigma campaigns could also increase the public knowledge about DG and could increase the treatment seeking level of the individuals with disordered gambling [9].

It is important to acknowledge that certain game types and their availability and easy accessibility are risk factors for the development of DG [44,65-67]. An alerting notion in two Finnish reports [41] is that of a new type of game that is offered via internet: internet slot machine games, where two addictive game types are combined with 24/7 accessibility. As a solution to these maintaining factors of gambling, Marshall [68] sets a good comparison on other public health issues, such as obesity, tobacco smoking and alcohol problems. In all of these public health issues the availability (e.g. fast food, cigarettes and alcohol) has worsened the condition at hand. Increasing the public awareness of the health issues involved, would give people more choice in their behaviour. This same approach is relevant and could also work with gambling issues.

Adams et al. [69] have brought up the question of how policy makers could respond to the harms caused by gambling. Harm minimization initiatives have been targeted into reducing availability and increasing education about harms of gambling. A good example from a harm minimization strategy comes from the Australian state of Victoria, where the number of Electronic Gambling Machines (EGM's) was reduced particularly in low-income communities, where the gambling was linked with harmful gambling [68,70]. Increasing such health promotion programs to include harms of gambling is recommended. As it is, expansion of commercial gambling is taking place on a global basis, especially internet gambling, which provides round-the-clock access to various gambling types, increasing the number of people getting involved and perhaps encountering some form of DG.

\section{Limitations}

First, a review of the population-based gambling studies indicates that the mean response rate in studies using telephone interview is generally $52.5 \%$ [10]. Therefore, the response rate of this study can be considered as low (39.9\%). Moreover, the proportion of young male 
participants was lower than the national average [11]. This is a typical phenomenon in gambling studies and an important notion since the prevalence of DG is typically high among young males [14-16]. The data weighting was performed to correct this bias. Second, the total number of problem gamblers and PG's was 106. However, international comparison indicates that this figure was higher than the international median of 52 [10]. Third, the SOGS instrument used in assessing gambling behaviour was originally developed in clinical context [24]. On the other hand, the version with a shorter time frame has been validated in a population-based study [71]. In this study, the internal consistency and reliability of the SOGS appeared to be good. Fourth, this study is limited by the crosssectional study design; therefore, no conclusions about the causal connection can be done. At the same time, the multinomial method used enhances the reliability since it notices the effect of the simultaneously analysed factors.

\section{Conclusion}

The consequences of gambling at societal, individual and familial level, calls for new actions both in Finland and internationally. Male gender and loneliness were found to be associated with problem gambling in particular, along with smoking and risky alcohol consumption. Mental health problems and risky alcohol consumption were associated with pathological gambling. These identified associations between disordered gambling, mental health problems and risky alcohol consumption should be taken into consideration when implementing more indepth and targeted screening of DG. It is also important to consider these associations when planning treatment of DG.

\section{Competing interests}

The authors declare that they have no competing interests.

\section{Authors' contribution}

The study design was develop by all authors. SC, SB, AHS, MP, HA, JER, TL have made substantial contributions to the analysis and interpretation of the data. SC, SB, AHS, MP, HA, TL have been involved in drafting the manuscript and revising it critically. All authors have given final approval of this version to be published.

\section{Acknowledgement \\ The authors thank Matthew Grainger for linguistic assistance.}

\section{Author details}

${ }^{1}$ National Institute for Health and Welfare, Department of Mental Health and Substance Abuse Services, P.O. Box 30 Helsinki, FO 00271 Finland. ${ }^{2}$ Institute of Behavioural Sciences, University of Helsinki, Faculty of Behavioural Sciences, Helsinki, Finland. ${ }^{3}$ Institute of Clinical Medicine, Department of Medicine, Research Unit of Substance Abuse Medicine, University of Helsinki, Helsinki, Finland. ${ }^{4}$ Department of Behavioural Sciences and Philosophy, University of Turku, Faculty of Social Sciences, Turku, Finland.

Received: 7 March 2013 Accepted: 20 June 2013

Published: 1 July 2013

\section{References}

1. Petry NM: Internet gambling: an emerging concern in family practice medicine? Fam Pract 2006, 23:421-426.

2. GRA (Gambling Research Australia): Problem gambling and harm: towards a national definition; 2005. http://www.adelaide.edu.au/saces/gambling/ publications/ProblemGamblingAndHarmTowardNationalDefinition.pdf

3. National Research Council (NRC): Pathological gambling: a critical review. Washington, D.C: National Academy Press; 1999.

4. Grinols EL: Gambling in America: costs and benefits. Cambridge: Cambridge University Press; 2004.

5. American Psychiatric Association (APA): Diagnostic and statistical manual of mental disorders. 4th edition. Washington DC; 1994.

6. Shaffer HJ, Hall MN, Vander BJ: Estimating the prevalence of disordered gambling behavior in the United States and Canada: a research synthesis. Am J Public Health 1999, 89:1369-1376.

7. Shaffer HJ, Hall MN: Updating and refining prevalence estimates of disordered gambling behavior in the United States and Canada. Can J Public Health 2001, 92:168-172.

8. Welte JW, Barnes GM, Wieczorek WF, Tidwell MC, Parker J: Gambling participation in the U.S.-results from a national survey. J Gamb/ Stud 2002, 18:313-337.

9. Hodgins DC, Stea JN, Grant JE: Gambling disorders. Lancet 2011, 378:1874-1884

10. Williams RJ, Volberg RA, Stevens RMG: The population prevalence of problem gambling: methodological influences, standardized rates, jurisdictional differences, and worldwide trends. Report prepared for the Ontario problem gambling research centre and the Ontario ministry of health and long term care. May 8, 2012. http://hdl.handle.net/10133/3068.

11. Turja T, Halme J, Mervola M, Jarvinen-Tassopoulous J, Ronkainen JE: Suomalaisten rahapelaaminen 2011 [Finnish Gambling 2011]. Helsinki: National Institute for Health and Welfare (THL). Report 14/2012.

12. Ashley $L L$, Boehlke KK: Pathological gambling: a general overview. J Psychoactive Drugs 2012, 44:27-37.

13. Winters KC, Stinchfield R, Fulkerson J: Patterns and characteristics of adolescent gambling. J Gamb/ Stud 1993, 9:371-386.

14. Lund I: Lessons from the grey area: a closer inspection of at-risk gamblers. J Gamb/ Stud 2007, 23:409-419.

15. Ladouceur R, Boudreault N, Jacques C, Vitaro F: Pathological gambling and related problems among adolescents. J Child \& Adolesc Subst Abuse 1999, 8:55-68.

16. Lyk-Jensen SV: New evidence from the grey area: Danish results for at-risk gambling. J Gamb/ Stud 2010, 2010(26):455-467.

17. Black DW, Moyer T: Clinical features and psychiatric comorbidity of subjects with pathological gambling behavior. Psychiatr Serv 1998, 49:1434-1439.

18. Cunningham-Williams RM, Cottler LB, Compton WM, Spitznagel EL: Taking chances: problem gamblers and mental health disorders-results from the St. Louis Epidemiologic Catchment Area Study. Am J Public Health 1998, 88:1093-1096.

19. Roy A: Pathological gambling: a psychobiological study. Arch Gen Psychiatry 1988, 45:369-373.

20. Lorains FK, Colishaw S, Thomas SH: Prevalence of comorbid disorders in problem and pathological gambling: systematic review and meta-analysis of population surveys. Addiction 2011, 106:490-489.

21. Volberg RA: The prevalence and demographics of pathological gamblers: implications for public health. Am J Public Health 1994, 84:237-241.

22. Cambell F, Lester D: The impact of gambling opportunities on compulsive gambling. J Soc Psychol 1999, 139:126-127.

23. Azmier J: Gambling in Canada 2005: statistics and context. Calgary: AB: Canada West Foundation; 2005

24. Lesieur HR, Blume SB: The South Oaks Gambling Screen (SOGS): a new instrument for the identification of pathological gamblers. Am J Psychiatry 1987, 144(9):1184-1188.

25. Bush K, Kivlahan DR, McDonell MB, Fihn SD, Bradley KA: The audit alcohol consumption questions (Audit-C): an effective brief screening test for problem drinking. Arch Intern Med 1998, 158:1789-1795.

26. Seppä K: Potilaan haastatteleminen: kolmen kysymyksen AUDIT-C [Interviewing a patient: three question AUDIT-C] Suomen lääkäriseura [Finish Association of Medical Doctors], Duodecim; 2010. http://www.kaypahoito.fi/web/kh/ suositukset/naytaartikkeli/.../nak04611 
27. Veit $C T$, Ware JE: The structure of psychological distress and well-being in general populations. J Consult Clin Psychol 1983, 51:730-742.

28. Berwick DM, Murphy JM, Goldman PA, Ware JE Jr, Barsky AJ, Weinstein MC Performance of a five-item mental health screening test. Medical Care 1991, 29:169-176.

29. Gerstein DR, Hoffmann JP, Larison C, Engelman L, Murphy S, Palmer A: Gambling impact and behavior study: report to the national gambling impact study commission. Chicago: National Opinion Research Center; 1999.

30. Ronnberg S, Volberg R, Abbott M, Moore L, Andén A, Munck I, et al: Spel och spelberoende I sverige [Gambling problems in Sweden]. Stockholm: Fölkhäsoinstitutet; 1999. Report No.3 I.

31. Sproston K, Ernst B, Orford J: Gambling behaviour in Britain: results from the British gambling prevalence survey. London: National Centre for Social Research; 2000.

32. Gotestam KG, Johansson A: Characteristics of gambling and problematic gambling in the Norwegian context: a DSM-IV-based telephone interview study. Addict Behav 2003, 28:189-197.

33. Lund I: Gambling and problem gambling in Norway: what part does the gambling machine play? Addiction Research \& Theory 2006, 14:475-491.

34. Blaszczynski AP, Buhrich N, McConaghy: Pathological gamblers, heroin addicts and controls compared on the E.P.Q. Addiction scale. Br J Addict 1985, 80(3):315-319.

35. Nower L, Derevensky $J \mathrm{~L}$, Gupta R: The relationship of impulsivity, sensation seeking, coping, and substance Use in youth gamblers. Psychology of Addictive Behaviour 2004, 1:49-55.

36. Bonnaire C, Bungener C, Varescon I: Subtypes of French pathological gamblers: comparison of sensation seeking, alexithymia and depression scores. J Gambl Stud 2009, 25:455-471.

37. Ladd $G$, Petry N: Gender differences among pathological gamblers seeking treatment. Exp Clin Psychopharmacol 2002, 10:302-309.

38. Brown S, Coventry L: Queen of hearts: the needs of women with gambling problems. Melbourne, Australia: Financial and Consumer Rights Council; 1997.

39. Trevorrow K, Moore S: The association between loneliness, social isolation and women's electronic gaming machine gambling. J Gambl Stud 1998, 14:263-284.

40. Volberg RA, Abbott MW, Rönnberg S, Munck IME: Prevalence and risks of pathological gambling in Sweden. Acta Psychiatr Scand 2001, 104:250-256

41. Williams RJ, Volberg RA: Impact of survey description, administration method, and exclusionary criteria on population prevalence rates of problem gambling. International Journal of Gambling Studies 2009, 9:101-117.

42. Williams RJ, Volberg RA: Best practices in the population assessment of problem gambling. Guelph, Ontario: Report submitted to the Ontario Problem Gambling Research Centre; 2010.

43. Lahti T, Halme J, Pankakoski M, Sinclair D, Alho H: Characteristics of treatment seeking Finnish pathological gamblers: baseline data from a treatment study. Int J Ment Heal Addict 2013, 11:307-314.

44. Jaakkola T, Murto A, Pajula M: Peliklinikan toimintakatsaus 2012 ja Peluurin puolivuotisraportti 2012 [Annual report of the gambling clinic of Helsinki, 2012 and half yearly report of gamblers helpline, Peluuri, 2012]. Unpublished Finnish report 2012 [http://www.peluuri.fi/data/liitteet/peliklinikka_ toimintakatsaus_2012_pdf.pdf].

45. Castrén S, Pankakoski M, Tamminen M, Lipsanen J, Ladouceur R, Lahti T: Internet-based CBT intervention for gamblers in Finland: experiences from the field. Scand J Psychol 2013, 54:230-235.

46. Griffiths M, Wood R, Parke J, Parke A: Gaming research and best practice: gaming industry, social responsibility and academia. Casino and Gaming International 2007, 3:97-103.

47. Rush B, Veldhuizen S, Adlaf E: Mapping the prevalence of problem gambling and its association with treatment accessibility and proximity to gambling venues. Journal of Gambling Issues 2007, 20:193-214.

48. Moore SM, Thomas AC, Kyrios M, Bates G, Meredyth D: Gambling accessibility: a scale to measure gambler preferences. J Gambl Stud 2011, 27:129-143.

49. Breen H: Risk and protective factors associated with gambling products and services: indigenous gamblers in north Queensland. Int J Ment Health Addiction 2012, 10:24-38.

50. Griffiths MD: Videogame addiction: fact or fiction? in Willoughby, T. \& Wood, E. (Eds.). Children's learning in a digital world (pp. 85-103). Oxford: Blackwell Publishing; 2007
51. Griffiths $M$, Wood R, Parke J: Reducing addiction risk in developing online games. World Online Gambling Law Report 2008, 7:15-6.

52. Griffiths M, Wood R: The psychology of lottery gambling. Int Gambl Stud 2001, 1:27-45

53. Blaszczynski A, McConaghy N, Frankova A: Boredom proneness in pathological gambling. Psychol Rep 1990, 67:35-42.

54. Tse S, Dyall L, Clarke D, Abbott M, Townsend S, Kingi P: Why people gamble: a qualitative study of four New Zealand ethnic groups. Int $J$ Ment Health Addiction 2012, 10:849-61. doi:10.1007/s11469-012-9380-7.

55. Petry NM: Psychiatric symptoms in problem gambling and Non-problem gambling substance abusers. Am J Addict 2010, 9:163-171.

56. Sylvain C, Ladouceur R, Boisvert JM: Cognitive and behavioral treatment of pathological gambling: a controlled study. J Consult Clin Psychol 1997, 65(5):727-32.

57. Toneatto T: Cognitive psychopathology of problem gambling. Subst Use Misuse 1999, 11:1593-1604.

58. Ladouceur R, Sylvain C, Boutin C, Doucet C: Understanding and treating pathological gamblers. London: Wiley; 2002.

59. Ladouceur R, Sylvain C, Boutin C, Lachance S, Doucet C, Leblond J: Group therapy for pathological gamblers: a cognitive approach. Behav Res Ther 2003, 41(5):587-596.

60. Toneatto T, Ladoceur R: Treatment of pathological gambling: a critical review of the literature. Psychol Addict Behav 2003, 17(4):284-292.

61. Petry NM, Ammerman Y, Bohl J, Doersch A, Gay H, Kadden R, Molina C, Steinberg K: Cognitive-behavioral therapy for pathological gamblers. J Consult Clin Psychol 2006, 74(3):555-567.

62. Ladouceur R, Lachance S: Overcoming pathological gambling. Therapist guide. N.Y.: Oxford University Press; 2007.

63. European commission: Commission sets out an action plan for online gambling; 2012. http://europa.eu/rapid/press-release_IP-12-1135_en.htm?locale=en.

64. Blaszczynski A, Ladouceur R, Shaffer HJ: A science-based framework for responsible gambling: the Reno model. J Gambl Stud 2004, 20:301-317.

65. Griffths M: Gambling technologies: prospects for problem gambling. J Gambl Stud 1999, 15:265-283.

66. Cox BJ, Yu N, Afifi T, Ladouceur R: A national survey of gambling problems in Canada. Can J Psychiatry 2005, 50:213-217.

67. Parke J, Griffths M: The psychology of fruit machine: the role of structural characteristics (revisited). Int I Ment Heal Addict 2006, 4:151-179.

68. Marshall D: Gambling as a public health issue: The critical role of the local environment. Journal of Gambling Issues 2009:66-80.

69. Adams PJ, Raeburn J, De Silva K: A question of balance: prioritizing public health responses to harm from gambling. Addiction 2009, 104:688-691.

70. Caraniche Pty Ltd (Caraniche): Evaluation of Electronic Gaming Machine Harm Minimisation Measures in Victoria. Melbourne: Department of Justice (Victoria); 2005

71. Abbot MW, Volberg A: The measurement of adult problem and pathological gambling. Int Gambl Stud 2006, 6(2):175-200.

doi:10.1186/1747-597X-8-24

Cite this article as: Castrén et al: Factors associated with disordered gambling in Finland. Substance Abuse Treatment, Prevention, and Policy 2013 8:24.

\section{Submit your next manuscript to BioMed Central and take full advantage of:}

- Convenient online submission

- Thorough peer review

- No space constraints or color figure charges

- Immediate publication on acceptance

- Inclusion in PubMed, CAS, Scopus and Google Scholar

- Research which is freely available for redistribution 